\title{
Life Cycle Modeling of Concrete Bridge Design: Comparison of Engineered Cementitious Composite Link Slabs and Conventional Steel Expansion Joints
}

\author{
Gregory A. Keoleian ${ }^{1}$; Alissa Kendall ${ }^{2}$; Jonathan E. Dettling ${ }^{3}$; Vanessa M. Smith ${ }^{4}$; Richard F. Chandler ${ }^{5}$; \\ Michael D. Lepech ${ }^{6}$; and Victor C. $\mathrm{Li}^{7}$
}

\begin{abstract}
Concrete infrastructure represents an enormous investment of materials, energy, and capital, and results in significant environmental burdens and social costs. There is an ongoing effort to identify material alternatives to conventional concrete. Life cycle assessment (LCA) is an important tool to evaluate the environmental performance of alternative infrastructure materials and systems. Here, we present a comparative LCA of two bridge deck systems over a 60 year service life: one using conventional steel expansion joints and the other based on a link slab design using a concrete alternative, engineered cementitious composites (ECC). The ECC link slab design is expected to extend the bridge deck service life and reduce maintenance activities. A life cycle model was developed that accounts for materials production and distribution, construction and maintenance processes, construction-related traffic congestion, and end-of-life management. Results indicate that the ECC bridge deck system has significant advantages in environmental performance: $40 \%$ less life cycle energy consumption, $50 \%$ less solid waste generation, and $38 \%$ less raw material consumption. Construction related traffic congestion is the greatest contributor to most life cycle impact categories.
\end{abstract}

DOI: 10.1061/(ASCE)1076-0342(2005)11:1(51)

CE Database subject headings: Energy consumption; Environmental impacts; Bridge design; Portland cements; Concrete pavements; Fiber reinforced materials.

\section{Introduction}

Several indicators demonstrate significant deficiencies in United States infrastructure systems. An estimated one-third of United States roadways are in poor or mediocre condition (ASCE 2001),

${ }^{1}$ Co-director, Center for Sustainable Systems, and Associate Professor, School of Natural Resources and Environment, 430 E. University, Univ. of Michigan, Ann Arbor, MI 48109.

${ }^{2}$ Graduate Student Research Assistant, Center for Sustainable Systems, School of Natural Resources and Environment, 430 E. University, Univ. of Michigan, Ann Arbor, MI 48109.

${ }^{3}$ Fellow, Great Lakes Commission, 2805 S. Industrial Hwy., Suite 100, Ann Arbor, MI 48104.

${ }^{4}$ Research Associate, Center for Sustainable Systems, School of Natural Resources and Environment, 430 E. University, Univ. of Michigan, Ann Arbor, MI 48109.

${ }^{5}$ Research Associate, Center for Sustainable Systems, School of Natural Resources and Environment, 430 E. University, Univ. of Michigan, Ann Arbor, MI 48109.

${ }^{6}$ Graduate Student Research Assistant, Dept. of Civil and Environmental Engineering, College of Engineering, 1328 George G. Brown Laboratories, 2350 Hayward St., Univ. of Michigan, Ann Arbor, MI 48019-2125.

${ }^{7}$ Professor, Dept. of Civil and Environmental Engineering, College of Engineering, 2326 George G. Brown Laboratories, 2350 Hayward St., Univ. of Michigan, Ann Arbor, MI 48019-2125.

Note. Discussion open until August 1, 2005. Separate discussions must be submitted for individual papers. To extend the closing date by one month, a written request must be filed with the ASCE Managing Editor. The manuscript for this paper was submitted for review and possible publication on January 26, 2004; approved on March 26, 2004. This paper is part of the Journal of Infrastructure Systems, Vol. 11, No. 1, March 1, 2005. CASCE, ISSN 1076-0342/2005/1-51-60/\$25.00. burdening the public with construction-related impacts such as congestion (TRIP 2002) and vehicle damage (ASCE 2001). Poor roadway conditions persist despite the continued investment in highways and roads of approximately 260 million t of concrete annually in the United States (Kelly 1998). This material flow represents both investment in repair and reconstruction of existing infrastructure as well as expansion of the national highway and road system. While United States consumption is significant, global construction related concrete production exceeds 12 billion t/year (van Oss and Padovani 2002). This production rate, which represents huge flows of material between natural and human systems, is expected to increase significantly as world population urbanizes (UNFPA 2001). While concrete consumption plays a key role in global development, cement, the key constituent in concrete, poses several major environmental challenges (van Oss and Padovani 2003). Cement production is energy intensive and accounts for $5 \%$ of global anthropogenic $\mathrm{CO}_{2}$ emissions (WBCSD 2002) and significant levels of $\mathrm{SO}_{2}, \mathrm{NO}_{x}$, particulate matter and other pollutants (USEPA 1999, 2000b). As global concrete, and thus cement production rise, so too will these related environmental burdens. Implementation of alternative materials in design and repair could serve to improve the environmental performance of concrete infrastructure.

Concrete's brittleness and limited durability under certain conditions lead to significant infrastructure failure and repairs. Alternative materials are being developed to improve the functional performance of concrete infrastructure systems. However, their introduction may be hindered by current material selection practices. Most state transportation departments select materials based on short-term measures rather than material performance over the life cycle of its application. Consequently, an alternative material 
may not be selected despite improved durability, and reduced maintenance and capital investment over the service life of the infrastructure.

Previously developed life cycle costing methods (Ehlen 1999) include agency and user costs (driver delay, vehicle operating, and vehicle accident costs) and third party costs. Ehlen classified third party costs as the upstream environmental costs associated with construction materials (pollution from mining, processing, and transportation) and the downstream environmental costs related to construction activities such as runoff (Ehlen 1999). While the increasing importance of third party costs were noted, they were not quantified and environmental impacts from construction related traffic delay were not identified in Ehlen's life cycle cost (LCC) model. A more holistic approach is necessary to evaluate materials based on their total LCC, including these externalities. Life cycle assessment (LCA) is an analytical framework (ISO 1997) for measuring environmental and social impacts of a product system or technology, and supplies a basis for comprehensive LCC evaluation.

The body of literature addressing LCA of bridge systems is very limited. Horvath and Hendrickson (1998) applied economic input-output life cycle assessment (EIO-LCA) to evaluate steel and steel reinforced concrete bridge girders. The EIO-LCA method traces economic transactions throughout the supply chain of a product system and evaluates resource requirements and environmental emissions using a commodity input-output model coupled with key environmental impact datasets. Horvath and Hendrickson's analysis focused on materials production, girder maintenance, and end-of-life management activities.

The present study employs process level LCA methods for a more complex infrastructure system whose more extensive system boundary encompasses the interface between the material elements of the bridge and roadway users, resulting in a more comprehensive environmental assessment for material selection. This life cycle model was developed and applied to compare the environmental impacts for a bridge containing conventional steel expansion joints, and an alternative design using link slabs constructed with a novel material—engineered cementitious composites (ECC).

The ECC is a particularly promising new class of materials for bridge, road, and pipe infrastructure repair. They are unique fiberreinforced materials with a microstructure design driven by micromechanical principles (Kanda and Li 1998; Li 1998). Unlike other concrete materials, ECC strain-hardens after first cracking, similar to a ductile metal, and demonstrates a strain capacity 500 600 times greater than normal concrete ( $\mathrm{Li}$ et al. 2003). Other characteristics of ECC include a fracture toughness like that of aluminum alloys (Maalej et al. 1995), extreme damage tolerance (Li et al. 2003), and ductility under severe shear loading conditions ( $\mathrm{Li}$ et al. 1994). ECC formulations are designed through microstructure tailoring of matrix, fiber, and fiber-matrix interfacial elements. ECC contains ingredients similar to fiber-reinforced concrete (e.g., water, cement, sand, fiber, and superplasticizer). However, coarse aggregates are notably absent. The amount of fiber in ECC is generally $2 \%$ or less by volume, facilitating selfconsolidating versions of ECC which can be mixed in gravity mixers or concrete mixing trucks and cast without vibrations. The ECC has been developed over the last decade, with development occurring worldwide (ECC Technology Network 2001). Potential infrastructure applications of ECC under investigation include building frames (Fischer and Li 2003), bridge piers, bridge deck repair (Gilani 2001), extruded pipes (Stang and Li 1999), and most recently roadway repairs.
There are a number of factors associated with substituting ECC for concrete that should be considered:

1. The use of ECC link slabs in concrete bridges is expected to extend the service life of the bridge deck and substructure and to reduce material consumption over the life of the bridge. Also, the superior properties of ECC could enable new design modes that currently do not exist.

2. The ECC infrastructure may require less frequent repair, thus reducing burdens related to congestion and vehicle repair. This affects fuel consumption and vehicle emissions, traffic delays, and freight productivity.

3. Mining and processing burdens associated with raw materials acquisition for ECC and concrete would vary depending on infrastructure service life.

4. The ECC costs two to three times more per unit volume than conventional concrete. In part, this reflects the higher energy intensity of ECC due to more cement and the addition of fibers in the mixture.

5. Demolition of ECC-based structures is expected to be more difficult because of its greater toughness.

These factors highlight the complexity of this study and emphasize the necessity of a holistic evaluation of potential bridge designs. The life cycle approach presented will be transferable to other infrastructure systems that are characterized by large societal investments, emergent materials, and complex issues of sustainability.

\section{Methods}

A life cycle inventory (LCI) model was created to evaluate environmental performance indicators for a bridge with either conventional mechanical steel expansion joints or with ECC link slabs. The LCI is carried out in accordance with ISO 14040 methods (ISO 1997) except for the critical review clause specified in Section 7.2 of the standard. While the critical review is required for comparative assertions, this study is intended to highlight the structure and capabilities of the LCA model for evaluation of long-term infrastructure applications rather than declaring the superiority of a particular bridge system. Environmental impact categories include energy and material resource consumption, air and water pollutant emissions, and solid waste generation. The indicators are evaluated for the total 60 year service life of a bridge. The life cycle assessment focuses on material production, construction, use, and end-of-life management stages related to bridge deck repair. Consequently, the initial bridge construction, which is common to both conventional and ECC systems, is excluded from this study.

\section{System Definition}

The bridge design analyzed in this study is based on an overpass with a steel reinforced concrete deck located between highways M-14 and US-23 in the state of Michigan. It is $0.1 \mathrm{mi}(160 \mathrm{~m})$ long, four lanes wide (two lanes in each direction), and the deck is 9 in. $(23 \mathrm{~cm})$ deep and rests on steel girders supported by a steel reinforced concrete substructure. For application in this LCA model, the bridge deck service life is assumed to be 30 years for the conventional steel-reinforced concrete system, and 60 years for the ECC system. The doubling of service life for the ECC system has yet to be validated with additional field and laboratory testing. These properties and design specifications are based on 


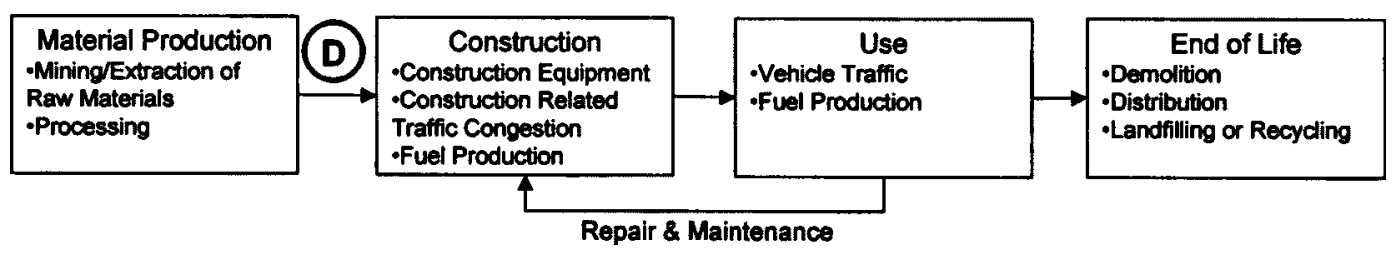

Fig. 1. Bridge deck life cycle phases ( $D=$ distribution)

estimates provided by a professional construction agency and results from a pilot study sponsored by the Michigan Department of Transportation (MDOT) (Li et al. 2003).

The bridge is estimated to have a traffic flow rate of 35,000 cars/day in each direction (MDOT 1997). Traffic flow remains constant for the duration of the bridge service life in the base scenario. As part of a sensitivity analysis, it is varied to explore the potential effects of alternate growth rates. Traffic composition is based on national average data (USEPA 2002).

The life cycle phases of the bridge are depicted in Fig. 1. Material production includes the acquisition and processing of raw materials into material inputs. Distribution of materials and transportation of equipment to and from construction sites is modeled. The construction stage includes all construction processes and construction related congestion effects. The use phase consists of vehicles traveling over the bridge during its 60 year service life. The end-of-life phase includes demolition of the bridge deck, transportation of the material to a landfill or recycling facility, and processing of the materials.

The bridge construction processes were specified with the assistance of University of Michigan civil engineers, a southeast Michigan construction company, and literature references (Ringwald 1993). The specifications included material quantities and equipment used in bridge construction, as well as a typical construction schedule.

A conventional mechanical steel expansion joint and an ECC link slab are illustrated in Fig. 2. The ECC link slab is $3 \mathrm{~m}$ long and is poured in direct contact with the adjoining concrete. The conventional joint consists of two steel expansion devices, with a rubber seal between them. There are three main reconstruction options for a bridge: bridge deck replacement, deck resurfacing, and repair and maintenance. Deck replacement is the most material and time intensive construction process and involves full depth replacement of the concrete on the deck and replacement of expansion joints and link slabs in the conventional and ECC systems, respectively. Resurfacing involves partial depth replacement of the concrete deck and includes joint replacement in the conventional system. Repair and maintenance is the least intensive process and mainly consists of fixing cracks and potholes. Girder maintenance requires painting to prevent corrosion. While girder painting is not included in the maintenance activities modeled here, its inclusion would likely favor the ECC system since the link slab design is expected to reduce corrosion for reasons described below.

A proposed construction schedule for the two systems was developed for the 60 year service life as shown in Fig. 3. The life cycle for each system begins with a deck replacement. It is assumed that with conventional joints the bridge deck will need replacement every 30 years, with a deck resurfacing and joint replacement every 15 years, and maintenance occurring every 5 years. In the ECC system, it is proposed that a single bridge deck will last the entire 60 year service life. Deck resurfacing occurs every 20 years, with maintenance at 10 year intervals.
The ECC link slabs are expected to extend the deck and surface life by preventing a few key deterioration modes. By protecting the deck's steel girders from corrosive elements that often leak through worn expansion joints, nearly all corrosion of the girders is prevented. Corrosion of the steel girders is one of the leading causes for replacement of the deck and superstructure. The superstructure includes the steel girders and bearings, but the components were not included in the scope of this inventory. However, extending the superstructure life would likely be an additional benefit to the ECC system. Resurfacing and maintenance is minimized since potholes and deck deterioration do not typically develop within the middle of the deck. Problems usually occur near the expansion joint for two reasons. First, since the concrete is exposed for its entire depth along the free expansion joint edge, it is more prone to be affected by corrosives and undergo carbonation near the joints leading to faster deck deterioration near the joints. Second, the dynamic loading of heavy trucks rolling over bumpy expansion joints wears the deck intensely right near the expansion joint, causing faster deterioration of the concrete. By eliminating expansion joints, these two scenarios are averted and resurfacing intervals extended to 20 years.

The total material contents of both bridge deck systems are shown in Table 1 for both the initial bridge deck replacement and the total life cycle. The energy intensity of each material and the source of life cycle inventory data for each material are also given.

\section{Life Cycle Inventory Model}

Data sets necessary for modeling the material production phase were obtained from various sources including the Portland $\mathrm{Ce}$ ment Association (2000 cement data for four kiln types over a wide range of efficiencies), DEAM ${ }^{\mathrm{TM}}$ (Ecobilan's Database for Environmental Analysis and Management), and the International Iron and Steel Institute (IISI 2000 steel data). For polyvinyl alco-

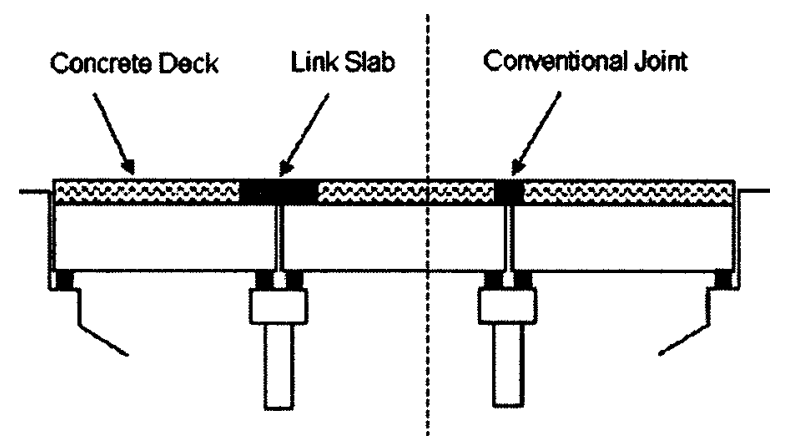

Fig. 2. Bridge deck with engineered cementitious composite link slab and conventional mechanical steel expansion joint 


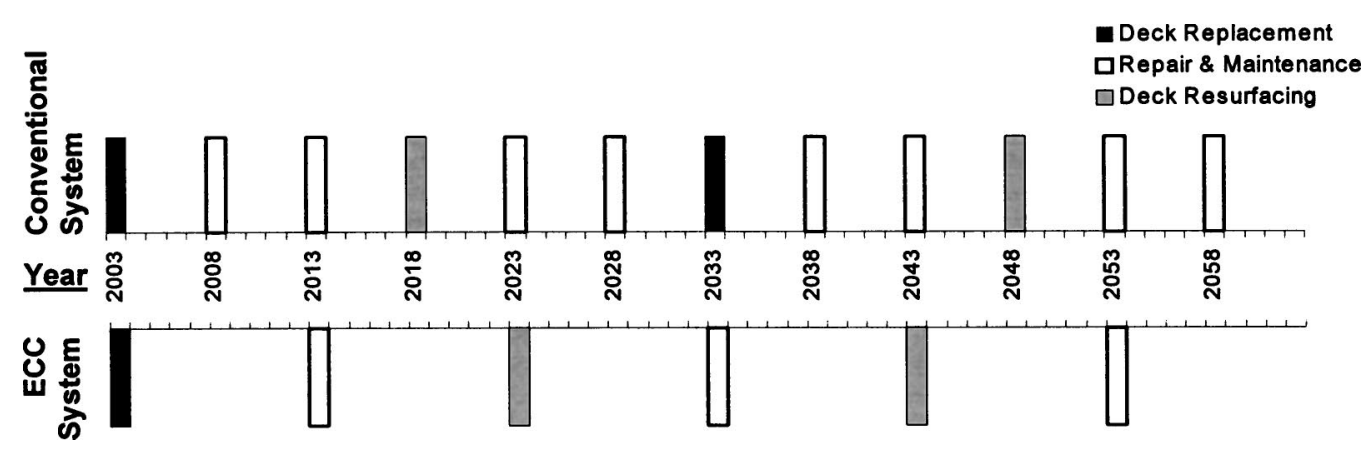

Fig. 3. Timeline for construction events

hol (PVA) fiber, a number of LCI data categories were provided by industry and the remaining were described with surrogate polyethylene data. The data fields supplied by the manufacturer are total primary energy consumption, carbon dioxide emissions, $\mathrm{NO}_{x}$ emissions, $\mathrm{SO}_{x}$ emissions, biological oxygen demand (BOD) discharge, chemical oxygen demand (COD) discharge, and waterborne suspended matter. Superplasticizer, a chemical additive used for processing ECC, was modeled using data for formaldehyde, the precursor to superplasticizer since no other data were available. The formaldehyde data were substituted by equal weight for the superplasticizer. Sources for all of these materials are listed in Table 1.

On a per volume basis, production of ECC consumes 1.8 times the energy consumed in the production of conventional steelreinforced concrete (1\% steel by volume). The total energy for steel reinforced concrete and ECC is 3,880 and $7,100 \mathrm{MJ} / \mathrm{m}^{3}$, respectively. The primary energy contribution for each material constituent is presented in Fig. 4. The ECC contains only slightly more cement than conventional concrete (18.5 compared to $15 \%$ for conventional), which might suggest similar energy intensities for the two materials. However, much of the additional energy in the production of ECC is attributed to the PVA fiber (2.1\% of total volume), which contributes $36 \%$ of total ECC material production energy. Fly ash, $25 \%$ of ECC by volume, is assumed to be a waste product of energy production, and consequently, environmental burdens were not allocated to this cement material substitute. Hence, fly ash does not contribute to the total energy consumed in the production of ECC. Fly ash was not considered for use in conventional concrete due to code restrictions in Michigan policy regarding concrete used in decks. As ECC link slabs are replacements for joints, rather than deck material, these restrictions do not apply.

The distribution of materials and equipment to the bridge site includes multimodal schemes, comprised of truck, rail, and seatanker combinations. Distribution distances were estimated using potential material supplier locations relative to the bridge site. Distribution environmental impacts result from fuel production and combustion.

Table 1. Use of Materials in Conventional and Engineered Cementitious Composite (ECC) Bridge Deck Systems and Associated Data Sources

\begin{tabular}{|c|c|c|c|c|c|c|c|}
\hline \multirow[b]{2}{*}{ Material } & \multicolumn{2}{|c|}{ Conventional system } & \multicolumn{2}{|c|}{ ECC system } & \multirow[b]{2}{*}{ Unit } & \multirow{2}{*}{$\begin{array}{l}\text { Energy } \\
\text { intensity } \\
(\mathrm{MJ} / \mathrm{kg})\end{array}$} & \multirow[b]{2}{*}{ Source of life cycle inventory information } \\
\hline & $\begin{array}{l}\text { Mass in } \\
\text { bridge deck }\end{array}$ & $\begin{array}{l}\text { Life cycle } \\
\text { bridge deck }\end{array}$ & $\begin{array}{l}\text { Mass in } \\
\text { bridge deck }\end{array}$ & $\begin{array}{l}\text { Life cycle } \\
\text { bridge deck }\end{array}$ & & & \\
\hline $\begin{array}{l}\text { Portland } \\
\text { cement }\end{array}$ & 242 & 608 & 233 & 327 & $\mathrm{t}$ & $4.5-6.6$ & $\begin{array}{l}\text { Portland Cement Association (PCA 2002) and Ecobilan } \\
\text { (Ecobilan 2001) cement data, } 1996\end{array}$ \\
\hline Gravel & 480 & 1,203 & 368 & 553 & $\mathrm{t}$ & 0.067 & $\begin{array}{l}\text { Portland Cement Association (PCA 2002), adjusted with } \\
\text { electricity and fuel production from Ecobilan (Ecobilan 2001). }\end{array}$ \\
\hline Sand & 335 & 840 & 295 & 425 & $\mathrm{t}$ & 0.067 & $\begin{array}{l}\text { Original Ecobilan sources: Various, 1985-94. Equipment } \\
\text { emissions from USEPA's } \\
\text { (USEPA 2000) }\end{array}$ \\
\hline Fly ash & 0 & 0 & 58 & 58 & $\mathrm{t}$ & 0 & $\begin{array}{l}\text { [Fly ash is a waste product associated with energy production; } \\
\text { therefore, no energy intensity is allocated.] }\end{array}$ \\
\hline PVA fiber & 0 & 0 & 2,124 & 2,124 & $\mathrm{~kg}$ & 101 & $\begin{array}{l}\text { Industry Source and polyethylene data from Association of } \\
\text { Plastic Manufacturers in Europe (Bousted 1999) }\end{array}$ \\
\hline $\begin{array}{l}\text { Super } \\
\text { plasticizer }\end{array}$ & 0 & 0 & 1,429 & 1,429 & $\mathrm{~kg}$ & 35 & $\begin{array}{l}\text { Formaldehyde data as surrogate for super plasticizer } \\
\text { (Ecobilan 2001). Primary Ecobilan source: Swiss Agency for } \\
\text { the Environment, Forests and Landscape (1994) }\end{array}$ \\
\hline Section steel & 377 & 754 & 377 & 377 & $\mathrm{t}$ & 9.5 & International Iron and Steel Institute (IISI 2000) \\
\hline Rebar steel & 31 & 63 & 31 & 31 & $\mathrm{t}$ & 8.4 & International Iron and Steel Institute (IISI 2000) \\
\hline Epoxy & 22 & 45 & 22 & 22 & $\mathrm{~kg}$ & 80 & $\begin{array}{l}\text { Ecobilan (Ecobilan 2001). Primary Ecobilan source: Perrin } \\
\text { and Scharff, (1993). }\end{array}$ \\
\hline Rubber & 88 & 353 & 0 & 0 & $\mathrm{~kg}$ & 84 & $\begin{array}{l}\text { Ecobilan (Ecobilan 2001). Primary Ecobilan sources: Various, } \\
\text { 1985-1989. }\end{array}$ \\
\hline Wood & 29 & 58 & 0.6 & 0.8 & $\mathrm{t}$ & 28 & $\begin{array}{l}\text { Ecobilan (Ecobilan 2001). Primary Ecobilan source: Western } \\
\text { Wood Products Association (WWPA) (1995). }\end{array}$ \\
\hline
\end{tabular}




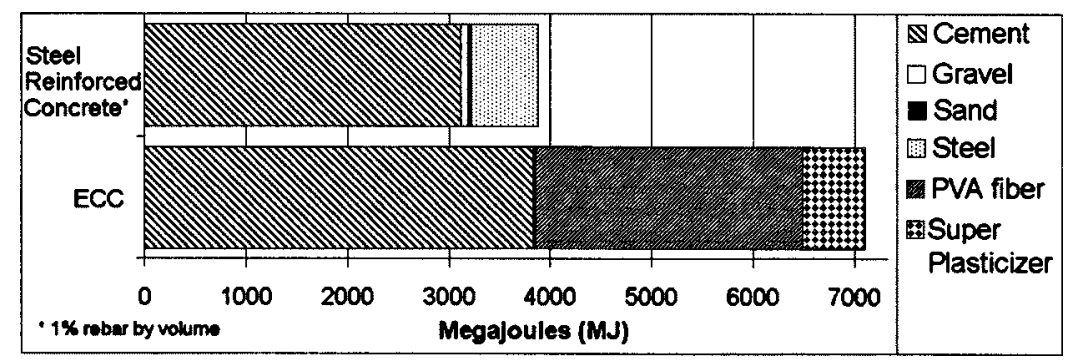

Fig. 4. Energy consumption per cubic meter of conventional steel-reinforced concrete and engineered cementitious composites

For the construction stage of the life cycle, estimates of each machine's operating times during the construction process were made, and fuel-related emissions were estimated using the United States Environmental Protection Agency (EPA) NONROAD model of diesel engine emissions (USEPA 2000a). The model allows specification of construction equipment based on 26 machinery types, and 15 horsepower classes. The equipment used during each modeled construction process is indicated in Table 2. Emission estimates are available from the NONROAD model for years through 2050. Construction events in the LCA model occurring after 2050 were based on 2050 emissions estimates. Fuel use estimates were obtained from the NONROAD model and upstream (extraction, processing, and distribution) burdens for this fuel were calculated using DEAM ${ }^{\mathrm{TM}}$ fuel production data.

Traffic congestion related to construction activities is included in the scope of this analysis. Traffic delays are estimated using the KyUCP model developed by the Kentucky Transportation Center (KTC 2002), which is based on methodology from the Federal Highway Administration. Construction related delays are calculated using model input parameters such as traffic flow rate, road capacity, work zone speed limits, lane width, and lane closure. During all construction events it is assumed that only one lane in each direction remains open to traffic. Speed limits are reduced from $70 \mathrm{mph}(113 \mathrm{~km} / \mathrm{h})$ to a work zone speed of $40 \mathrm{mph}(64$ $\mathrm{km} / \mathrm{h}$ ). Since drivers are expected to self-detour under heavy traffic conditions the model included three detour routes that drivers were likely to take, with $12 \%$ of the total traffic diverted. In all cases the detours were assumed to be on nonhighway roads, thus resulting in slower travel speeds and longer travel distances. Because traffic volume is an important determinant of traffic delay, estimating future trends in traffic can play an enormous role in determining the environmental impacts of construction projects. Automobile emission estimates were generated using US EPA's MOBILE6.2 software (USEPA 2002). Emissions were modeled at various speeds. Predictions are available from the MOBILE6.2 software on a per year basis through 2050. For years following 2050, the 2050 emission estimates are used. MOBILE6.2 accounts for tailpipe emissions as well as evaporative emissions. In addition to vehicle emissions, the amount of excess fuel consumed as a result of delays was calculated and emissions from the production of this fuel were inventoried. Fuel consumption for cars and trucks was determined based on city and highway drive cycle estimates of fuel economy. Data for cars came from US EPA fuel economy data and commercial truck data from The Technology Roadmap for the 21st Century Truck Program (Bradley 2000; Hellman and Heavenrich 2003). A city drive cycle is the closest estimate of fuel economy available for modeling stop-and-go movement typical of congestion. Likewise, a highway drive cycle for normal traffic flow is used to model flow during nonconstruction and noncongestion periods.

Energy use, fuel consumption, and emissions for the traffic stage is always calculated based on the difference between traffic flow during construction periods and the baseline scenario under normal highway flow conditions. Henceforth this differential is

Table 2. Equipment Usage During Construction Activities in Hours Per Construction Event

\begin{tabular}{|c|c|c|c|c|c|c|}
\hline Equipment & $\mathrm{kW}$ & $\begin{array}{l}\text { Conventional } \\
\text { system } \\
\text { deck replacement } \\
\text { with joints }\end{array}$ & $\begin{array}{c}\text { Engineered } \\
\text { cementitious } \\
\text { composite system deck } \\
\text { replacement } \\
\text { with link slabs }\end{array}$ & $\begin{array}{l}\text { Conventional system } \\
\text { resurfacing and } \\
\text { joint replacement }\end{array}$ & $\begin{array}{c}\text { Engineered } \\
\text { cementitious } \\
\text { composite } \\
\text { system resurfacing }\end{array}$ & $\begin{array}{l}\text { Maintenance } \\
\text { and repair }\end{array}$ \\
\hline $\begin{array}{l}\text { Crawler-mounted } \\
\text { hydraulic excavator }\end{array}$ & 319 & 128 & 128 & 0 & 0 & 0 \\
\hline Air compressor & 261 & 64 & 128 & 48 & 0 & 0 \\
\hline Concrete mixer & 6 & 0 & 0 & 0 & 0 & 16 \\
\hline Concrete paving machine & 186 & 96 & 32 & 32 & 32 & 0 \\
\hline Concrete truck & 224 & 32 & 32 & 32 & 32 & 0 \\
\hline Crane, $50 \mathrm{t}$ & 132 & 176 & 176 & 0 & 0 & 0 \\
\hline Dumper & 17 & 128 & 192 & 80 & 32 & 0 \\
\hline Hydraulic hammer & 75 & 64 & 128 & 0 & 0 & 0 \\
\hline Motor grader & 123 & 0 & 0 & 16 & 16 & 0 \\
\hline Signal boards & 4 & 18,000 & 24,480 & 7,680 & 4,992 & 0 \\
\hline Vacuum truck & 132 & 0 & 0 & 32 & 32 & 0 \\
\hline Water truck & 336 & 0 & 0 & 32 & 32 & 0 \\
\hline Wheeled front end loader & 175 & 624 & 688 & 48 & 0 & 0 \\
\hline
\end{tabular}


Table 3. Life Cycle Raw Material Resource Use

\begin{tabular}{lcc}
\hline Raw material & $\begin{array}{c}\text { Conventional } \\
\text { system } \\
(\mathrm{t})\end{array}$ & $\begin{array}{c}\text { Engineered cementitious } \\
\text { composite system } \\
(\mathrm{t})\end{array}$ \\
\hline Coal & 124 & 67 \\
Limestone & 757 & 406 \\
Natural gas & 140 & 84 \\
Oil & 590 & 368 \\
Sand & 852 & 443 \\
Water & 24,696 & 15,351 \\
\hline
\end{tabular}

designated as $\Delta$ traffic in subsequent tables and figures.

The use phase of the life cycle consists of vehicles traveling over the bridge during a 60 year service life. Again, automotive emissions are based on MOBILE6.2 data. The impacts from this stage of the life cycle are highly dependent on patterns of change in fuel economy and traffic growth rate over the service life of the bridge. Multiple growth scenarios have been explored. Results show that the use phase of the life cycle, which consists of vehicle travel over the length of the bridge, constituted $90-99 \%$ of the overall life cycle energy use and emissions for most automotiverelated pollutants. This stage of the life cycle is therefore left out of much of the analysis for the following reasons: (1) as modeled, there are no differences in the use phase between the two systems and (2) the magnitude of the use phase emissions obscure emission quantities from the other phases. It should also be noted that the use phase is directly proportional to bridge length, whereas other components, such as traffic congestion, are mostly independent of bridge length.

Because of improved integrity and slower deterioration of the ECC system bridge deck, it is plausible that there would be differences in automobile efficiency and road-related damage to automobiles using the ECC system. Although this change would account for only a small percentage of use phase energy consumption, the magnitude of the use phase burdens in relation to the other parts of the life cycle indicates that these factors could represent a significant portion of the total life cycle burden. Because of the difficulty in measuring the impact of road surface on automobile fuel economy and vehicle damage for this analysis, these components are not currently included in the model.

For the end-of-life phase, the base case assumes that most material is landfilled. None of the concrete materials are reused or recycled. Steel is the only exception with a $20 \%$ recycling rate. Information detailing the demolition process was obtained from a professional construction contractor, including machinery and construction process requirements. Transportation of bridge materials to the landfill site is modeled in the same manner as the distribution phase (transport between material production and construction sites).

\section{Results}

A comparative assessment for a conventional steel reinforced bridge deck and an ECC link slab system over a 60 year time horizon is presented by the life cycle phase. Total life cycle results include impacts from the material production, distribution, construction, and end-of-life phases. The environmental impacts studied include resource consumption, global warming potential, air pollutant emissions, and water pollutant discharges. As explained in the "Methods" section the use phase, namely normal

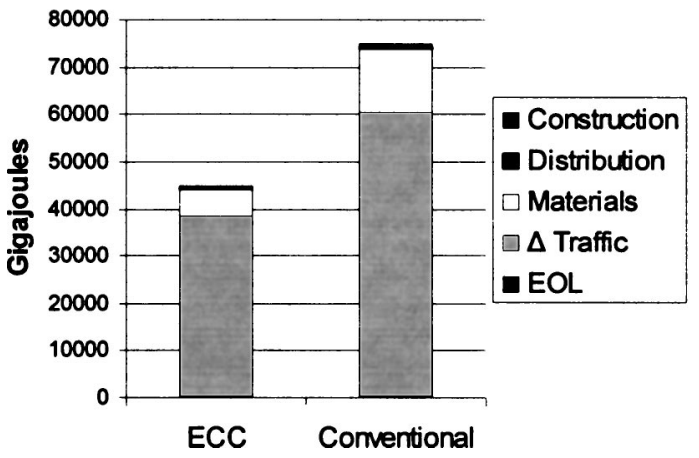

Fig. 5. Total primary energy consumption by life cycle stage

traffic flow over the bridge, impacts are omitted from the total life cycle results.

\section{Life Cycle Inventory}

\section{Raw Material Resource Consumption}

Consumption of raw material resources is shown in Table 3. The ECC system results in a net savings of both energy and material mineral resources. Of the resources shown in Table 3, the percent change in resource use reduction between the ECC and conventional systems ranges from 38 to $48 \%$ in favor of ECC.

\section{Energy Consumption}

Despite the higher energy intensity of ECC, its physical properties are expected to extend the service life of the ECC system to twice that of the conventional system, resulting in significantly less total life cycle energy consumption, as shown in Fig. 5.

From a life cycle perspective, total energy consumption for both systems modeled is dominated by traffic-related energy consumption as is evident in Fig. 5. As indicated in the "Methods" section, traffic related energy consumption represents the differential between normal flow conditions and traffic flow during construction periods. The only other contributor to energy consumption on the scale of traffic related energy is material production energy. While ECC material production energy use is higher on a per-volume basis, from a life cycle perspective the conventional concrete system requires more energy since considerably more material is used over the 60 year life of the bridge.

\section{Greenhouse Gas Production}

The distribution of greenhouse gas $(\mathrm{GHG})$ emissions is similar to those for energy consumption. Traffic related carbon dioxide $\left(\mathrm{CO}_{2}\right)$ dominates total GHG production for both the ECC and conventional bridge systems. Material production is the only other significant contributor. Fig. 6 shows the total GHG emissions in ton of $\mathrm{CO}_{2}$ equivalent for each system. This is calculated by multiplying the mass of each GHG emission by its global warming potential (GWP). The GWPs are based on the radiative forcing (heat absorbing ability) of each GHG as well as the decay rate of each gas relative to carbon dioxide over a 100 year time horizon. The GHG emissions included in this analysis are $\mathrm{CO}_{2}(\mathrm{GWP}=1)$, methane $(\mathrm{GWP}=23)$, and nitrous oxide (GWP =296) (Houghton 2001). Despite the contribution to global warming of the two other gases, $\mathrm{CO}_{2}$ overwhelmingly dominates GWP. 


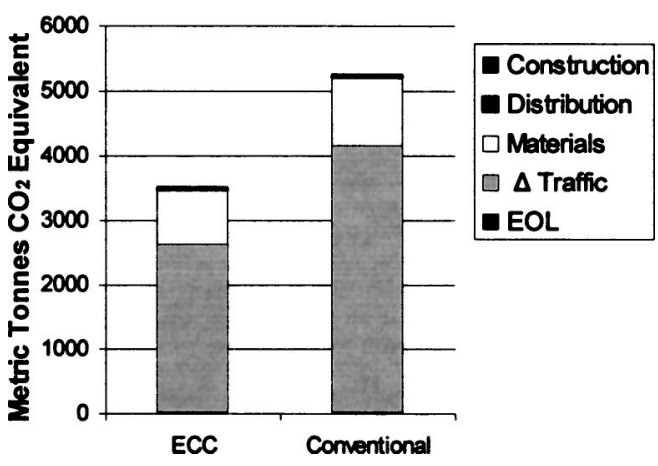

Fig. 6. Total global warming potential by life cycle phase

In the ECC system $\mathrm{CO}_{2}$ represents $98 \%$ of total life cycle GWP, and in the conventional system $\mathrm{CO}_{2}$ represents $99 \%$ of total life cycle GWP. The ECC system shows a reduction of $33 \%$ in GWP over the conventional system. Typically, $\mathrm{CO}_{2}$ emissions mirror energy consumption; however, the production of cement involves the release of additional $\mathrm{CO}_{2}$ during pyroprocessing (conversion of calcium carbonate to calcium oxide), which results in twice the $\mathrm{CO}_{2}$ that would be produced from energy consumption alone (CEMBUREAU 1998). This additional contribution of $\mathrm{CO}_{2}$ from cement production is evident in the comparison of Figs. 5 and 6 wherein material production represents a greater portion of the total $\mathrm{CO}_{2}$ production than it does total energy consumption.

\section{Select Air Pollutant Emissions}

Other select air emissions in addition to $\mathrm{CO}_{2}$ include nitrogen oxides $\left(\mathrm{NO}_{x}\right)$, sulfur oxides $\left(\mathrm{SO}_{x}\right)$, nonmethane hydrocarbons (NMHCs), particulate matter $\left(\mathrm{PM}_{10}\right)$, carbon monoxide $(\mathrm{CO})$, and methane $\left(\mathrm{CH}_{4}\right)$. Fig. 7 shows that the ECC system emits significantly less of each of these pollutants over the 60 year time horizon. The $\mathrm{NO}_{x}$ emissions warrant an explanation since the results are not intuitive. This pollutant shows negative values for the traffic phases for both ECC and conventional. This results because $\mathrm{NO}_{x}$ is produced in greater quantities at high speeds than at low speeds. So while most pollutants are increased by congestion, $\mathrm{NO}_{x}$ is an exception to the rule. When the baseline results are subtracted from the construction phase traffic results, the consequence is a negative value for $\mathrm{NO}_{x}$ emissions. Timing of construction events over the 60 year service life drives the superior results for ECC. For $\mathrm{NO}_{x}$ emissions, there is a "benefit" associated with construction events only in the short term because of expected reductions in $\mathrm{NO}_{x}$ emissions at high speeds in the future. For the ECC bridge deck system, deck replacement occurs only at Year 1. This construction event is estimated to take a total of 68 days, 18 days longer than a conventional deck replacement takes. The 68 days comprise $55 \%$ of the total number of construction days in the bridge's lifecycle, meaning that the construction activities for the ECC lifecycle are weighted heavily towards the first year. Because of this weighting of construction days early in the ECC system timeline, the results for ECC show more negative $\mathrm{NO}_{x}$ values than the conventional system.

\section{Water Pollutant Discharges}

Emissions to water from each life cycle stage are shown in Fig. 8. The ECC system results in a $34-76 \%$ reduction of water pollutants. The large emissions of suspended matter, oils, and BOD from the traffic phase result from fuel production processes.

\section{Solid Waste Production}

Life cycle solid waste generation totaled 3,970 t for the conventional system, and 2,000 t for the ECC system, approximately half the solid waste generation of the conventional system. In both systems, bridge materials constitute the majority of solid waste, accounting for $87 \%$ in the ECC system and $90 \%$ in the conventional system.

\section{Sensitivity Analysis}

The model was developed using a simulation of two hypothetical systems. Generalizations were made regarding construction timing and processes, and traffic flow, thus introducing a significant level of uncertainty into the model. Consequently, sensitivity analysis was performed on several key parameters.

Fig. 9 shows the sensitivity of the energy consumption from construction related traffic to changes in the traffic volume growth rate. The base scenario involves a steady traffic rate of 35,000 vehicles/day in each direction. A $12 \%$ diversion rate results in 30,800 vehicles/day passing through the construction zone, and a maximum traffic queue of $0.11 \mathrm{mi}(0.18 \mathrm{~km})$. However, under a $1 \%$ growth rate, the traffic volume grows to 60,500 in Year 2058,
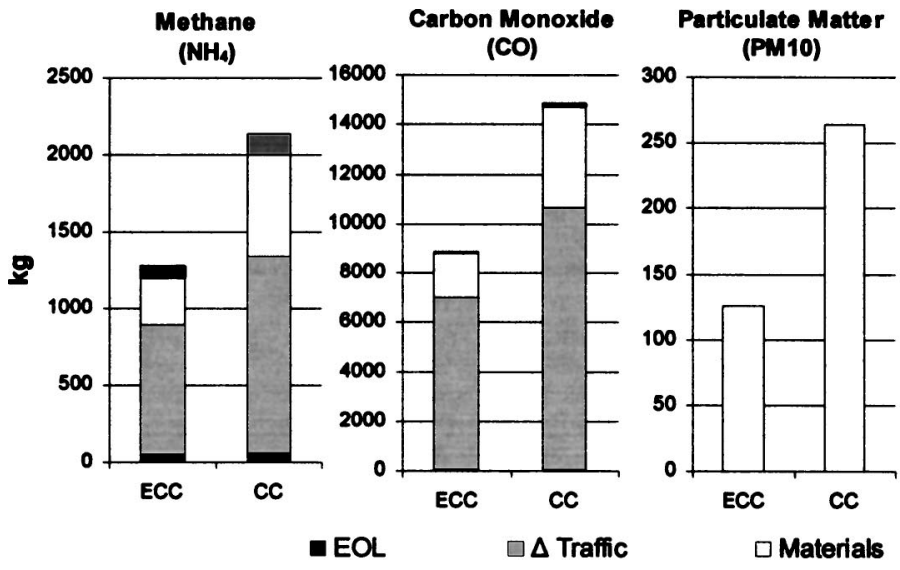
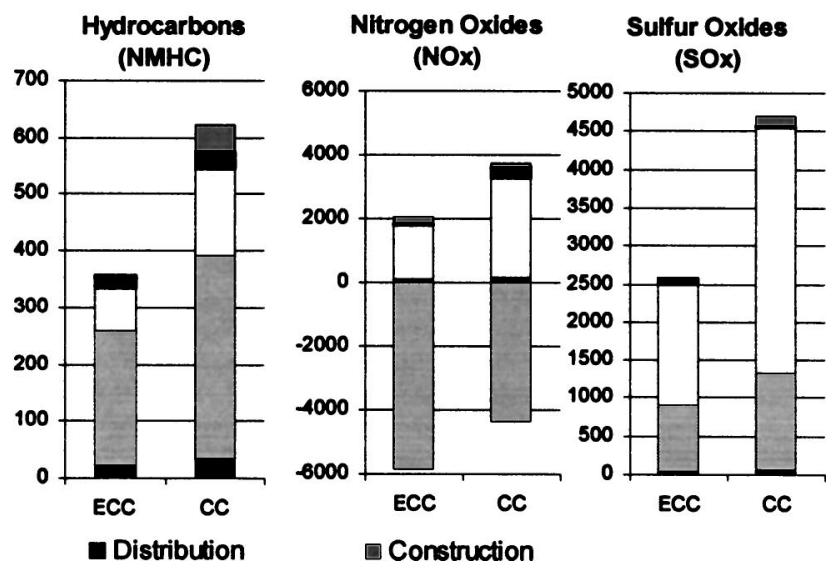

Fig. 7. Air emissions by life cycle stage 

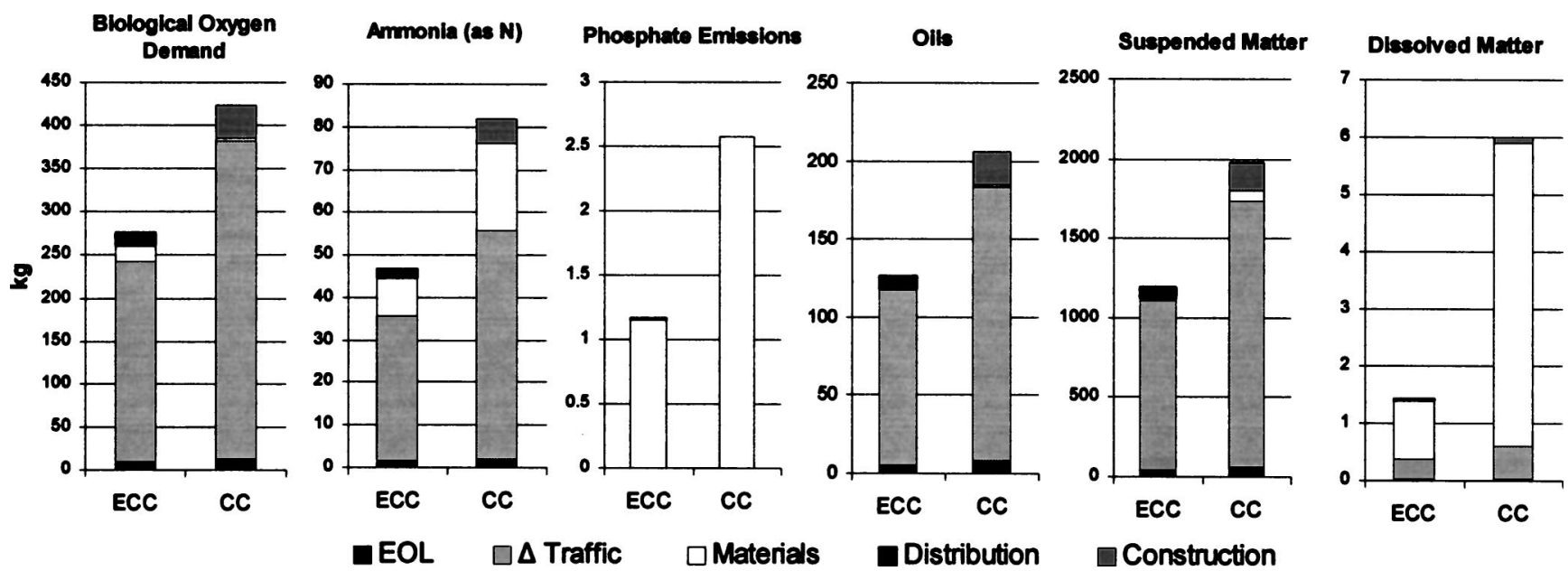

Fig. 8. Water pollution discharges by life cycle stage

resulting in a maximum traffic queue of $15.2 \mathrm{mi}(24.5 \mathrm{~km})$. This length is perhaps unrealistic and is partially a product of the inability of the model to account for increased diversion with growing queue length and the potential for new highways and roads. Nevertheless, this analysis shows that the traffic congestion component of the model has the potential to overwhelm life cycle energy of other elements in the model under significant traffic growth scenarios. Fig. 9 shows growth scenarios of 0,1 , and $2 \%$. At $2 \%$ growth, traffic related energy consumption grows to more than 13 and 23 times the $0 \%$ growth levels for the ECC and conventional systems, respectively. Considering that United States annual vehicle miles traveled is increasing by more than $2 \%$ per year on average, there is a potential for traffic related congestion to overwhelm all of the other elements in the LCA. In real world terms, however, motorists are likely to pursue alternate routes or modes of transport, and transportation agencies are likely to expand and build new roads under this traffic growth scenario, so such backups on a single roadway seem unlikely.

In addition to our base case, which uses cement produced from the relatively inefficient wet process, we have examined the effect of several common, more efficient cement kiln types in Table 4. Use of a more efficient kiln type such as the dry process with preheater and precalciner could reduce total material production energy by as much as $10 \%$ for the conventional system and $27 \%$ for the ECC system. The type of kiln used could therefore be a major contributor to differences in life cycle impacts between geographical regions, considering that cement plant types vary regionally.

\section{Discussion}

Financial cost and prescribed material specifications currently guide the selection of materials for infrastructure applications. Broader environmental, social, and economic issues related to life cycle impacts of infrastructure systems have gone unrecognized. The method applied in this paper uses a comprehensive set of environmental metrics to evaluate a novel infrastructure material over the entire life cycle of the bridge deck. This method may be applied to other infrastructure materials and systems as well. The results indicate that the limited application of ECC in bridge deck link slabs has the potential to improve environmental performance of the bridge infrastructure system. The LCA can aid in the incorporation of environmental impacts into infrastructure planning decisions. Moreover, the LCA model provides a basis for LCC, which would inform agencies and decision-makers of the private and social costs of choosing one material over another. Concrete infrastructure involves huge material flows, significant energy consumption, and environmental impacts. Incorporation of alternative cementitious materials can reduce the size of these burdens by extending the service life of the systems, which minimizes material use and results in less frequent reconstruction.

This study is novel in the breadth of its system boundary. The boundary of previous work was extended by incorporating the numerous construction processes that occur throughout the bridge service life and by evaluating their effects on highway congestion. The results demonstrate that these phases account for a significant portion of total life cycle impacts, and that construction and repair frequencies are key drivers in determining environmental impacts. The traffic model used in the current study took into account a constant diversion rate of $12 \%$ during construction events. In the future, a more responsive traffic model that varies diversion rates based on backup queue length could be employed for more accurate modeling of driving behavior.

One of the strengths of this life cycle model is the inclusion of the US EPA emission models, NONROAD and MOBILE6.2, which provide projections of future vehicle emissions through the year 2050. However, all other data sets used in the model did not account for improvements in emission levels over time. Therefore, it is likely that many of the impacts calculated for future

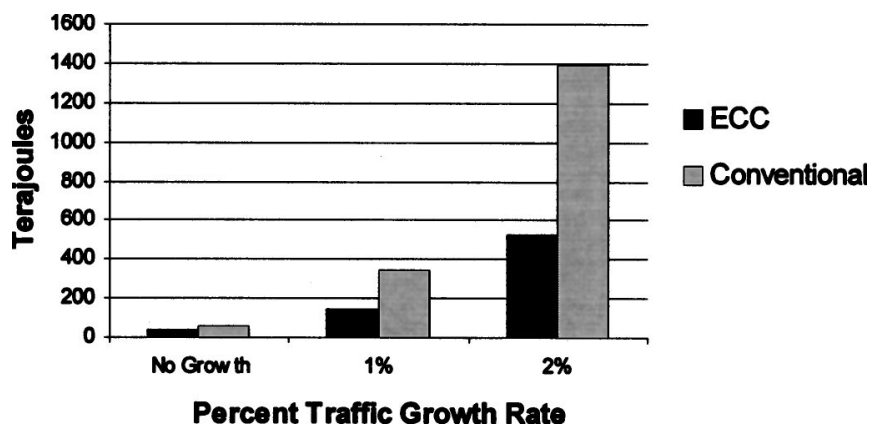

Fig. 9. Sensitivity of construction related total primary $\Delta$ traffic energy to changes in annual traffic growth rate 
Table 4. Sensitivity of Total Material Production Energy to Changes in Cement Kiln Type

\begin{tabular}{|c|c|c|c|c|}
\hline \multirow[b]{2}{*}{ Kiln type } & \multicolumn{2}{|c|}{ Total production energy $(\mathrm{TJ})$} & \multicolumn{2}{|c|}{ Difference from wet process $(\%)$} \\
\hline & Conventional & ECC & Conventional & ECC \\
\hline Wet process & 13.48 & 5.01 & - & - \\
\hline Long dry process & 13.18 & 4.68 & 2.3 & 6.5 \\
\hline Dry process with preheater & 12.47 & 3.92 & 7.5 & 21.8 \\
\hline Dry process with preheater and precalciner & 12.24 & 3.67 & 9.2 & 26.8 \\
\hline Weighted US national average & 12.72 & 4.24 & 5.6 & 15.4 \\
\hline
\end{tabular}

Note: ECC $=$ engineered cementitious composites.

construction events have been slightly overestimated. Another consideration is uncertainty in model parameters. Of those examined, variations in traffic growth rate showed a significant effect. Exploration of various scenarios suggests the burdens associated with construction related traffic are highly sensitive to these rate changes. As future trends are difficult to predict, and will be location-specific, uncertainty is inherent in traffic growth projections and associated congestion modeling. Given the sensitivity of impacts to traffic flow, location-specific considerations such as rural versus urban roads, and future land development planning all play a role in determining the magnitude of traffic related emissions. Moreover, the magnitude of traffic related impacts also suggests that system level alternatives, such as installation of mass transport systems, or changes in land development patterns, should be sought.

A major underlying assumption of the study is the specification of the ECC system service life as twice that of the conventional system. While this assumption is supported by results of physical property testing, it is implicitly uncertain and can only be verified with the actual application of ECC in a bridge deck system and observation of its performance over time. The large improvement resulting with the ECC system implies that even with a lower expected performance, ECC could still prove advantageous for this application. Additionally, there remains the possibility that the doubling of the ECC system service life could prove to be an underestimation, resulting in even better life cycle performance. Exploring these other service life scenarios will be an important topic of future work.

One prospect on the frontier of ECC development is the incorporation of alternative materials. "Green" ECC mixtures (environmentally preferable mixtures) are being developed which utilize industrial byproducts as material substitutes (e.g., fly ash for Portland cement, foundry sand or shredded office plastic for sand, and textile waste cuttings for virgin polymer fibers), resulting in greatly reduced resource depletion with acceptable decrease in physical performance. Our results suggest that materials acquisition and processing accounts for the second largest portion of total lifecycle burdens in many categories, such as energy consumption and global warming. The use of alternative materials has the potential to significantly decrease the environmental burdens associated with the material production phase, without compromising the material's ability to fulfill the requirements of a particular application.

\section{Conclusion}

This study showed that the ECC link slab bridge deck design resulted in significantly lower environmental impacts over a 60 year bridge deck service life compared to the conventional steel expansion joint system. A key finding from life cycle modeling was the importance of construction related traffic on the environmental performance of both deck systems. Predicting maintenance and repair schedules for each system is critical in evaluating the performance of alternative materials. This analysis was based on the assumption that the ECC link slab would double the life expectancy of the bridge deck relative to the conventional steel joint. Life cycle modeling enables decision makers to explore a variety of scenarios to better understand the potential impacts of large-scale systems over long timeframes.

Improvements in the sustainability of infrastructure will require improved material selection criteria. The diverse nature of impacts, the long-lived nature and consequences of infrastructure systems, and institutional barriers for implementing new materials, highlight the complexity involved when evaluating new material choices. The method outlined in this paper presents a comprehensive tool for material selection and bridge design. This life cycle model extends the scope of a conventional LCA by accounting for the dynamic nature of the interlinked bridge and traffic systems. This model explored the dynamics of vehicle emissions and vehicle miles traveled which were key determinants of environmental impact. Future refinements in the model will consider the changes over time in other life cycle parameters such as material production energy intensities and emission factors.

The LCA model developed in this study can serve as a foundation for a comprehensive life cycle cost model to enhance infrastructure sustainability and investment decisions (Norris 2001). The LCA and LCC models have previously been integrated for several other product systems including automotive parts (Keoleian and Kar 2003) and photovoltaics (Keoleian and Lewis 2003). The LCA model is essential to measure the magnitude of the pollution externalities that can be monetized using unit damage costs from environmental economics. The infrastructure system investigated in this study, however, represents a greater modeling challenge given its complexity in terms of the continual material and capital investments over a long service life.

\section{Acknowledgments}

This research was funded through an NSF MUSES Biocomplexity Program Grant (Nos. CMS-0223971 and CMS-0329416). MUSES (Materials Use: Science, Engineering, and Society) supports projects that study the reduction of adverse human impact on the total interactive system of resource use, the design and synthesis of new materials with environmentally benign impacts on biocomplex systems, as well as the maximization of efficient use of materials throughout their life cycles.

\section{References}

American Society of Civil Engineers (ASCE). (2001). Renewing America's infrastructure: A citizen's guide, Reston, Va. 
Bousted, I. (1999). "Ecoprofiles of plastics and related intermediates." Association of Plastics Manufacturers in Europe, Brussels, Belgium.

Bradley, R. (2000). "Technology Roadmap for the 21st Century Truck Program." U.S. Department of Energy: Energy Efficiency and Renewable Energy, Washington, D.C.

ECC Technology Network. (2001). "An international network sharing ECC technology." 〈http://www.engineeredcomposites.com/html/ members.html $\rangle$ (January 23, 2004).

Ecobilan. (2001). "TEAM/DEAM.” Ecobilan, PriceWaterhouseCoopers, Rockville, Md.

Ehlen, M. A. (1999). "Life-cycle costs of fiber-reinforced-polymer bridge decks." J. Mater. Civ. Eng., 11(3), 224-230.

European Cement Association (CEMBUREAU). (1998). "Climate change, cement and the EU." Brussels, Belgium.

Fischer, G., and Li, V. C. (2003). "Intrinsic response control of moment resisting frames utilizing advanced composite materials and structural elements." ACI Struct. J., 100(2), 166-176.

Gilani, A. (2001). "Link slabs for simply supported bridges: Incorporating engineering cementitious composites.” MDOT SPR-54181, Structural Research Unit, Michigan Department of Transportation, Lansing, Mich.

Hellman, K. H., and Heavenrich, R. M. (2003). "Light-duty automotive technology and fuel economy trends: 1975 Through 2003." EPA420R-03-006, United States Environmental Protection Agency, Ann Arbor, Mich.

Horvath, A., and Hendrickson, C. (1998). "Steel versus steel-reinforced concrete bridges: Environmental assessment." J. Infrastruct. Syst., 4(3), 111-117.

Houghton, J. T. (2001). "Contributions of working group I to the third assessment report of the intergovernmental panel on climate change." Climate change 2001: The scientific basis, Cambridge University Press, New York, 388.

International Iron and Steel Institution (IISI). (2000). "Worldwide LCI database for steel industry products." IISI, Brussels, Belgium.

International Organization for Standardization (ISO). (1997). "Environmental management-Life cycle assessment-Principles and framework." ISO 14040, Geneva, Switzerland.

Kanda, T., and Li, V. C. (1998). "Multiple cracking sequence and saturation in fiber reinforced cementitious composites." Jpn. Concr. Inst. Concr. Res. Technol., 9(2), 19-33.

Kelly, T. (1998). "Crushed cement concrete substitution for construction aggregates-A materials flow analysis." Circular 1117, United States Geological Survey.

Keoleian, G. A., and Kar, K. (2003). "Elucidating complex design and management tradeoffs through life cycle design: Air intake manifold demonstration project." J. Cleaner Prod., 11(1), 61-77.

Keoleian, G. A., and Lewis, G. (2003). "Modeling the life cycle energy and environmental performance of amorphous silicon BIPV roofing in the US." Renewable Energy, 28(2), 271-293.

Kentucky Transportation Center (KTC). (2002). "The cost of construction delays and traffic control for life-cycle cost analysis of pavements." KTC-02-07/SPR197-99 \& SPR218-00-1F, Lexington, Ky.

Li, V., Fischer, G., Kim, Y., Lepech, M., Qian, S., Weimann, M., and Wang, S. (2003). "Durable link slabs for jointless bridge decks based on strain-hardening cementitious composites." Project Rep., Michigan Department of Transportation, Lansing, Mich.

Li, V. C. (1998). "Engineered cementitious composites-Tailored composites through micromechanical modeling." Fiber reinforced con- crete: Present and the future, N. Banthia, A. Bentur, and A. Mufti, eds., Canadian Society for Civil Engineering, Montréal, 64-97.

Li, V. C., Mishra, D. K., Naaman, A. E., Wight, J. K., Wu, H. C., and Inada, Y. (1994). "Shear behavior of engineering cementitious composites." J. Adv. Cement Based Mater., 1(3), 142-149.

Maalej, M., Hashida, T., and Li, V. C. (1995). "Effect of fiber volume fraction on the off-crack-plane fracture energy in strain-hardening engineered cementitious composites." J. Am. Ceram. Soc., 78(12), 3369-75.

Michigan Department of Transportation (MDOT). (1997). "1997 noninterstate freeway segments: Deficient segments-URBAN." MDOT, Ann Arbor, Mich.

Norris, G. (2001). "Integrating life cycle cost analysis and LCA." Int. J. Lifecycle Assess., 2(6), 118-120.

Perrin, R., and Scharff, J. P. (1993). Chimie Industrielle, Vol. 1, Masson, Paris.

Portland Cement Association (PCA). (2002). "Environmental life cycle inventory of Portland cement concrete. Appendix: Life cycle inventory of Portland cement manufacture." PCA, Skokie, Ill.

Ringwald, R. C. (1993). Means heavy construction handbook, R.S. Means Company, Kingston, Mass.

Stang, H., and Li, V. C. (1999). "Extrusion of ECC-material." Processing of high performance fiber reinforced cement composites 3, H. Reinhardt and A. Naaman, eds., Chapman \& Hall, London, 203-212.

Swiss Agency for the Environment, Forests, and Landscape. (2002). "Comparative environmental evaluation of construction paints and varnishes." No. 232, Vol. 2, Swiss Agency for the Environment, Forests, and Landscape, Bern, Switzerland, 74-76.

The Road Information Program (TRIP). (2002). "Key facts about America's road and bridge conditions and federal funding."TRIP, Washington, D.C.

The United Nations Population Fund (UNFPA). (2001). "The state of world population 2001." UNFPA, New York, Chap.3.

United States Environmental Protection Agency (USEPA). (1999). “40 CFR part 63 national emission standards for hazardous air pollutants for source categories; Portland cement manufacturing industry; final rule." USEPA, Washington, D.C.

United States Environmental Protection Agency (USEPA). (2000a). "NONROAD." Ann Arbor, Mich.

United States Environmental Protection Agency (USEPA). (2000b). "Sources of dioxin-like compounds in the United States. Draft exposure and human health reassessment of 2,3,7,8-tetrachlorodibenzo-pdioxin (TCDD) and related compounds." Rep. No. EPA/600/P-00/001 $B b$, Environmental Protection Agency.

United States Environmental Protection Agency (USEPA). (2002). MOBILE 6.2, Ann Arbor, Mich.

van Oss, H. G., and Padovani, A. C. (2002). "Cement manufacture and the environment. Part I: Chemistry and technology." J. Ind. Ecol., 6(1), 89-105.

van Oss, H. G., and Padovani, A. C. (2003). "Cement manufacture and the environment, Part II: Environmental challenges and opportunities." J. Ind. Ecol., 7(1), 93-126.

Western Wood Products Association (WWPA). (1995). "Eco profile of lumber produced in the western United States." WWPA and Scientific Certification Systems, inc., Oakland, Calif.

World Business Council on Sustainable Development (WBCSD). (2002). "Toward a sustainable cement industry." Draft Rep. Battelle Memorial Institute/WBCSD, Geneva. 